\title{
INVESTIGATION INTO TIME DEPENDANT DEGRADATION AND ATMOSPHERIC CONDITIONS ON THE WETTABILITY OF NYLON 6,6 WHICH HAS UNDERGONE $\mathrm{CO}_{2}$ LASER SURFACE MODIFICATION
}

Paper (201)

\author{
D.G. Waugh ${ }^{1}$, J. Lawrence ${ }^{1}$ and D.J. Morgan ${ }^{2}$ \\ ${ }^{1}$ Wolfson School of Mechanical and Manufacturing Engineering, Loughborough University, Leicestershire, \\ LE11 3TU, UK \\ ${ }^{2}$ Cardiff Catalysis Institute, School of Chemistry, Cardiff University, Cardiff, CF10 3AT, UK
}

\begin{abstract}
Modification of the wettability of polymers has been demonstrated previously; however, it is known that the wettability modifications of these materials can degrade or vary over time. This can be seen to be crucial from a commercial point of view as this would indicate that a shelf-life has to be established. But at the same time, atmospheric parameters may affect the contact angle and must therefore be accounted for as a control variable in any long-term study of wettability. In this study four $\mathrm{CO}_{2}$ laser patterned nylon 6,6 samples with differing topographical patterns and one as-received sample were analysed over a 30 week period whilst stored in ambient air. By obtaining the characteristic contact angle every two weeks it was found that the contact angle varied erratically before ultimately increasing for all samples after the 30 weeks. White light interferometry analysis determined that the laser patterning gave rise to peak heights of up to $3 \mu \mathrm{m}$ with roughness parameters $\mathrm{Ra}$ and $\mathrm{Sa}$ of up to 0.305 and $0.408 \mu \mathrm{m}$, respectively. X-ray photoelectron spectroscopy found that surface oxygen content increased by up to $7 \%$ At. It was identified that there was a significant correlation between changes in barometric air pressure and contact angle, highlighting the need for further study to determine if this is a dominant factor.
\end{abstract}

\section{Introduction}

Wettability can be seen as a potential driving force in numerous applications such as biomedical [1-3] and adhesion $[4,5]$. For each of these applications it can be seen that, in general, the researcher employs the wettability characteristics to predict how a surface is going to react after treatment in relation to the anticipated application. From work such as this, one can extrapolate that it would be more commercially viable to have the ability to know how a process is going to modify a surface and ultimately be able to predict how that modified surface will perform during it's intended use. As a direct result of this, it can be seen through available literature that wettability is a major focus point for numerous researchers $[1,6,7]$.

It has been shown that two wetting regimes can arise: Wenzel and Cassie-Baxter wetting regimes $[8,9]$. In general it is seen that hydrophilic surfaces (contact angles $<90^{\circ}$ ) give rise to Wenzel regimes meaning the whole surface comes into contact with the incident liquid. On the other hand, those surfaces which are predominantly hydrophobic (contact angles $>90^{\circ}$ ) possess characteristics that are explained using the Cassie-Baxter regime which assumes a liquid-solid interface with air-gaps formed between the liquid and solid surfaces. Furthermore, in some instances it has been observed that a surface modified hydrophilic material can give rise to an increase in contact angle with the sample still remaining hydrophilic $[1,10]$. This can be explained with the introduction of a mixed intermediate state wetting regime which gives rise to the inclusion of both Wenzel and Cassie-Baxter regimes $[10,11]$.

Regardless of the dominant wetting regime, it has been shown that the surface topography and surface chemistry on both the micro- and nano- scales can have major effects on the wettability characteristics of a material [12-15]. In order to induce these surface modifications a large number of techniques have been identified and demonstrated such as employing plasma surface modification [16,17], coating technologies $[18,19]$, lithography [15,20], radiation grafting [21]. Another is that of laser technology, which offers numerous benefits such as clean non-contact processing, flexibility and the ability to accurately modify the surface properties of a material without modifying the bulk properties. The latter benefit allows one to see that lasers can be employed to applications such bio-implant materials which require the surface to be modified for enhanced bioactivation whilst keeping the already sufficient bulk properties in tact $[2,22]$.

A number of various long term studies have been carried out investigating the effect of different 
parameters on the wettability of a material over a set amount of time [23-26]. In addition to long term studies it has also been observed that the differing atmospheric pressure and differing environments can have a major effect on the wettability of a material as seen by Li et al. [27], Hansen et al. [28] and Siemons et al. [29].

Although $\mathrm{CO}_{2}$ lasers have been shown to be capable of modifying the wettability of polymeric materials, it is known that the wettability modifications of these materials can vary over time. But at the same time, ambient atmospheric parameters will affect the contact angle and must therefore be accounted for as a control variable in any long-term study of wettability. This can be seen to be crucial from a commercial point of view as this would indicate that a shelf-life has to be established. As a result, a unique study has been undertaken by analysing how the wettability varies over time and how atmospheric parameters effect the contact angle of four $\mathrm{CO}_{2}$ laser patterned nylon 6,6 samples with differing topographical patterns and one as-received sample.

\section{Experimental Procedures}

\section{$\mathrm{CO}_{2}$ Laser Patterning}

The nylon 6,6 was sourced in $100 \times 100 \mathrm{~mm}^{2}$ sheets with a thickness of $5 \mathrm{~mm}$ (Goodfellow Cambridge, Ltd). To obtain a conveniently sized sample for experimentation the as-received nylon sheet was cut into $30 \mathrm{~mm}$ diameter discs using a $1 \mathrm{~kW}$ continuous wave (cw) $\mathrm{CO}_{2}$ laser (Everlase S48; Coherent, Ltd). No discernible heat affected zone (HAZ) was observed under optical microscopic examination.

In order to generate the required marking pattern with the $10.6 \mu \mathrm{m}$ Synrad cw 10W CO $\mathrm{CO}_{2}$ laser system Synrad Winmark software version 2.1.0, build 3468 was used. In addition, the software was capable of using images saved as .dxf files which can be produced by using CAD programs such as, in this case, Licom AutoCaM. The sample material was held in the system with a bracket on a variable $\mathrm{z}$-axis stage and was positioned at the focal length, which was $250 \mathrm{~mm}$ from the laser aperture to the sample surface. The laser system utilized a galvanometer scanner to scan the $95 \mu \mathrm{m}$ spot size beam directly across the stationary target material. It should be noted that the target material and laser system was held in a laser safety cabinet in which the ambient gas was air and an extraction system was used to remove any fumes produced during laser processing.
4 nylon samples were patterned differently in regards to topographical feature: $50 \mu \mathrm{m}$ spacing (A3), hatch with $50 \mu \mathrm{m}$ spacing (B1), trenches with $100 \mu \mathrm{m}$ spacing (B2) and hatch with $100 \mu \mathrm{m}$ spacing (B3). In addition, an as-received control sample was used (A1). For each of the irradiated patterns the laser power was set to $70 \%(7 \mathrm{~W})$ operating at $600 \mathrm{mms}^{-1}$.

\section{Topography, Wettability and Surface Chemistry} Analysis

Surface profiles of the nylon 6,6 samples were determined using a white light interferometer (WLI) (NewView 500; Zygo Ltd, USA) with MetroPro and TalyMap Gold Software before and after the 30 week experimental period. The Zygo WLI was setup using a $\times 10$ Mirau lens with a zoom of $\times 0.5$ and working distance of $7.6 \mathrm{~mm}$. This system also allowed $\mathrm{Sa}$ and $\mathrm{Ra}$ roughness parameters to be determined for each sample.

The samples were ultrasonically cleaned in isoproponal (Fisher Scientific Ltd., UK) for 3 minutes at room temperature before using a sessile drop device to determine various wettability characteristics, in accordance with the procedure detailed by Rance [30]. This was to allow for a relatively clean surface prior to any contact angle measurements being taken. A sessile drop device (OCA20; Dataphysics Instruments, $\mathrm{GmbH})$ was used in conjunction with specific software (SCA20; Dataphysics Instruments, $\mathrm{GmbH}$ ) so that the recent advancing and receding contact angles for triply distilled water and the recent advancing angle for diodomethane could be determined for each sample. This was repeated every two weeks throughout the 30 week period. By achieving the advancing and receding contact angles the hysteresis for the system was determined. This was done by using the 'needle in' method to accurately add or remove liquid to give the advancing and receding liquid-solid-vapour line, respectively. In addition, by knowing the advancing contact angles for the two liquids it was possible to use the software to draw a Owens, Wendt, Rabel and Kaeble (OWRK) plot to determine the surface energy of the samples. For the two reference liquids the SCA20 software used the Ström et al. technique to calculate the surface energy of the material. It should be noted here that 10 contact angles, using 2 droplets, in each instance was recorded to achieve a mean contact angle for each liquid-surface interface. Atmospheric data was recorded using a portable weather station (Meteo Clock Evolution Advance SM1840; Lexibook, S.A.). 

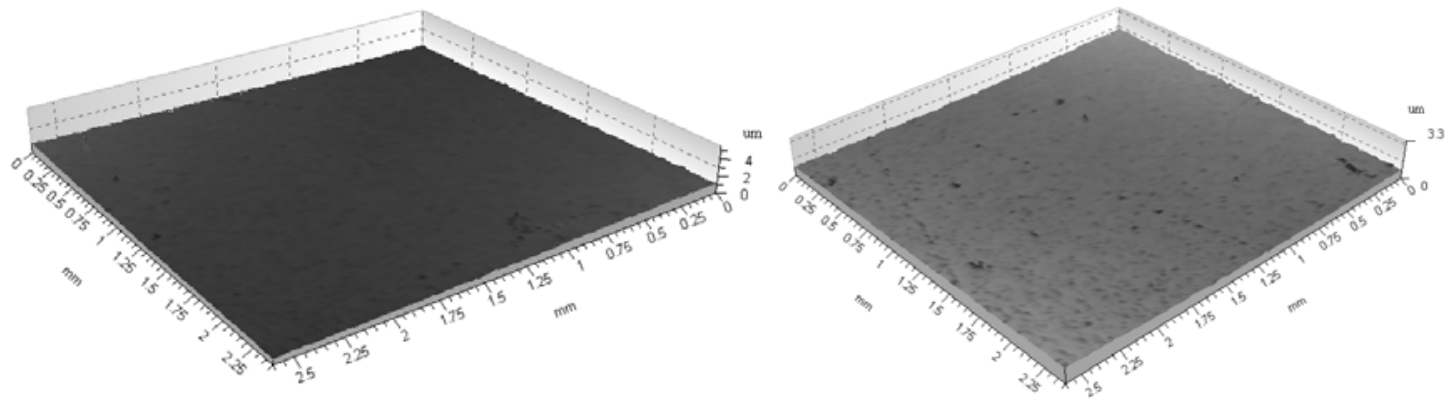

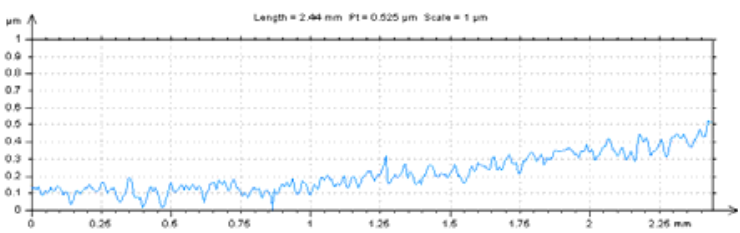

(a)

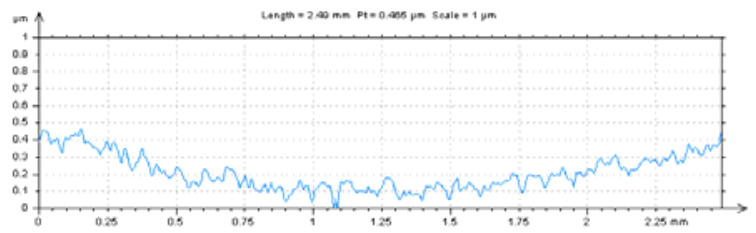

(b)

Figure 1 - Continuous axonometrics and profile extractions for the as-received sample (A1) - (a) week 0 and (b) week 30.

Each sample was also analysed before and after the study by using X-ray photoelectron spectroscopy (XPS) to allow any surface modifications in terms of chemical composition due to the laser patterning to be revealed. Also, XPS was used to identify any changes within the surface chemical composition that may have come about over the experimental period. Further details of the XPS experimental procedure are described in [1].

\section{Results and Discussion}

\section{Effect of Time on Topography}

Over time it was believed that it may be possible for the surface topographies to degrade. As such, it was necessary to analyse the samples using WLI before and after the experimental period to assess whether any changes had occurred during this time. This allowed 3D continuous axonometrics, profile extractions and roughness values for the sample surfaces to be determined in each instance.

Figure 1 shows the continuous axonometric and profile extraction for the as-received sample at weeks 0 and 30. It can be seen from Figure 1 that, in terms of peak heights and surface features, the as-received surface topography did not vary over the 30 week period. This is confirmed with the profile extraction shown in Figure 1 with the peak heights observed to be, at most, $0.5 \mu \mathrm{m}$ after 30 weeks. This is also confirmed by the roughness parameters, shown in Table 1, in that the $\mathrm{Sa}$ and $\mathrm{Ra}$ did not change over the allotted time for the asreceived sample.

In order to identify any variations in surface topography over the 30 week experimentation period for the laser patterned samples WLI analysis was employed. The results for the laser patterned samples is detailed in Table 1 and Figures 2 to 5.

Table 1 - Surface roughness values for $\mathrm{Ra}$ and $\mathrm{Sa}$ before and after the long term experiment for each

\begin{tabular}{|l|c|c|c|c|}
\cline { 2 - 5 } \multicolumn{1}{c|}{} & \multicolumn{2}{c}{ Week 0} & \multicolumn{2}{c|}{ Week 30} \\
\hline Sample & $\mathrm{Ra}$ & $\mathrm{Sa}$ & $\mathrm{Ra}$ & $\mathrm{Sa}$ \\
$(\mu \mathrm{m})$ & $(\mu \mathrm{m})$ & $(\mu \mathrm{m})$ & $(\mu \mathrm{m})$ \\
\hline $\begin{array}{l}\mathrm{A} 1 \\
(\text { As-received })\end{array}$ & 0.028 & 0.111 & 0.032 & 0.100 \\
\hline $\begin{array}{l}\text { A3 } \\
(50 \mu \mathrm{m} \text { trench })\end{array}$ & 0.238 & 0.537 & 0.213 & 0.312 \\
\hline $\begin{array}{l}\mathrm{B} 1 \\
(100 \mu \mathrm{m} \text { trench })\end{array}$ & 0.305 & 0.375 & 0.235 & 0.297 \\
\hline $\begin{array}{l}\mathrm{B} 2 \\
(50 \mu \mathrm{m} \text { hatch })\end{array}$ & 0.200 & 0.408 & 0.212 & 0.385 \\
\hline $\begin{array}{l}\mathrm{B} 3 \\
(100 \mu \mathrm{m} \text { hatch })\end{array}$ & 0.202 & 0.285 & 0.274 & 0.323 \\
\hline
\end{tabular}



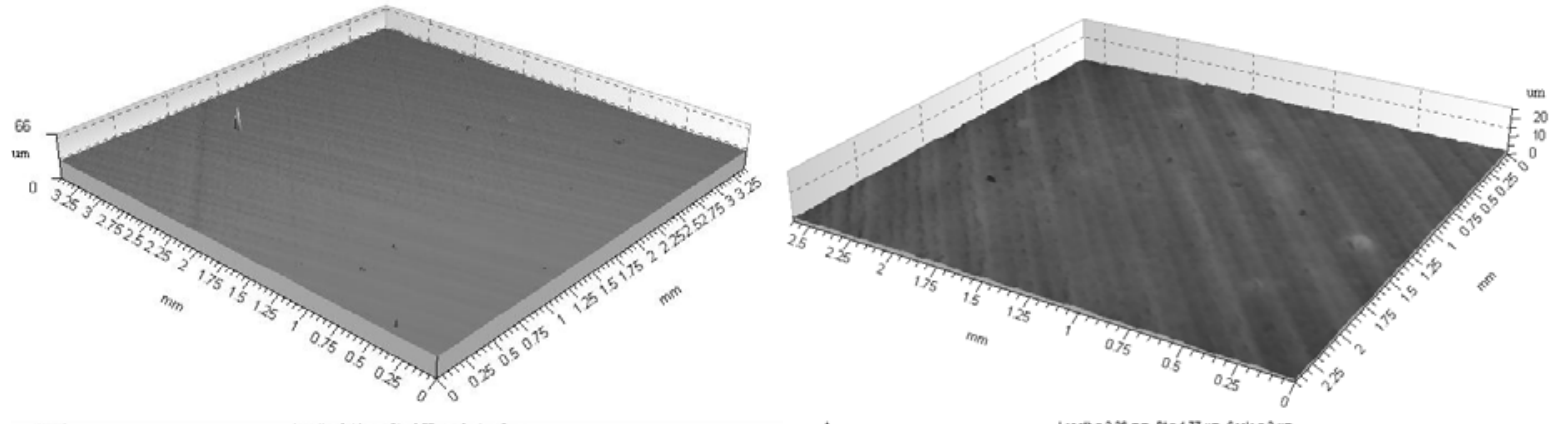

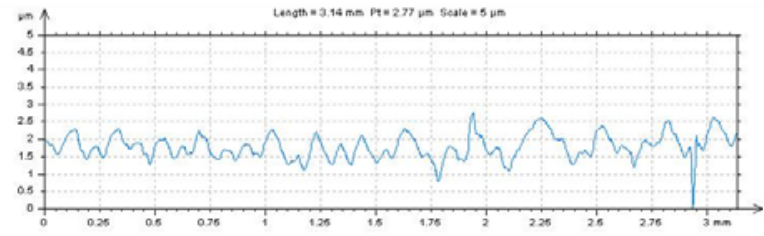

(a)

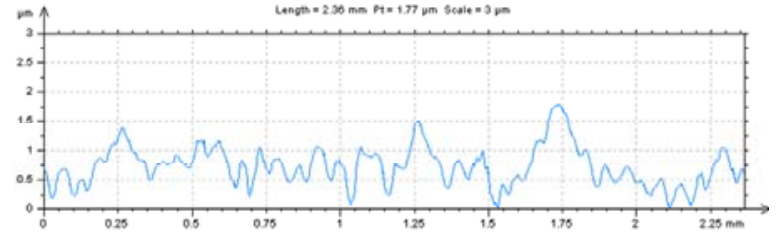

(b)

Figure 2 - Continuous axonometrics and profile extractions for the $50 \mu \mathrm{m}$ trench pattern (A3) - (a) week 0 and (b) week 30 .

Through WLI analysis for the $50 \mu \mathrm{m}$ trench pattern (sample A3) shown in Figure 2 it was seen that in terms of surface topography there was no significant difference between week 0 and week 30 . This coincides with what was observed for the as-received sample (A1) shown in Figure 1. By means of the $\mathrm{CO}_{2}$ laser patterning of the $50 \mu \mathrm{m}$ trench pattern (sample A3) it can be seen through the profile extraction shown in Figure 2 that there does appear to be some slight periodicity to the pattern induced; however, less periodicity can be identified after the 30 week experiment. With regards to maximum peak heights for the $50 \mu \mathrm{m}$ trench pattern it can be seen in Figure 2 that they remained around $2 \mu \mathrm{m}$ over the 30 week testing period. From Table 1 it can be seen that the

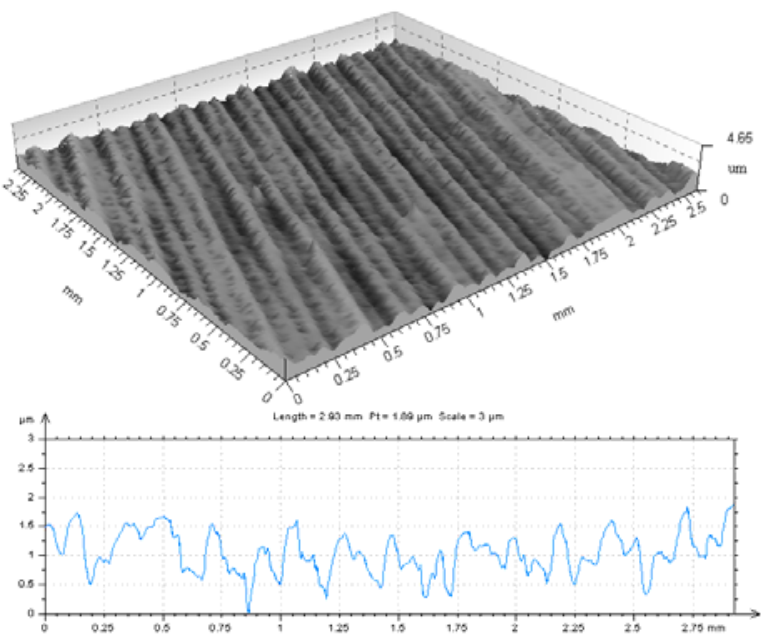

(a) surface roughness parameter Ra remained equivalently constant after 30 weeks with the Ra for week 0 being $0.238 \mu \mathrm{m}$ and week 30 being $0.213 \mu \mathrm{m}$. For the roughness parameter $\mathrm{Sa}$ it was found that this value decreased over time with the sample surface giving an Sa of 0.537 and 0.312 for week 0 and week 30, respectively. This could be on account of degradation of the surface topography over time.

Figure 3 shows the 3-D continuous axonometric and profile extraction for the laser induced $100 \mu \mathrm{m}$ trench pattern (sample B1) before and after 30 weeks. Firstly, it can be seen that in comparison to the $50 \mu \mathrm{m}$ trench pattern (see Figure 2) the $100 \mu \mathrm{m}$ trench pattern (sample B1) has a more defined periodic pattern.
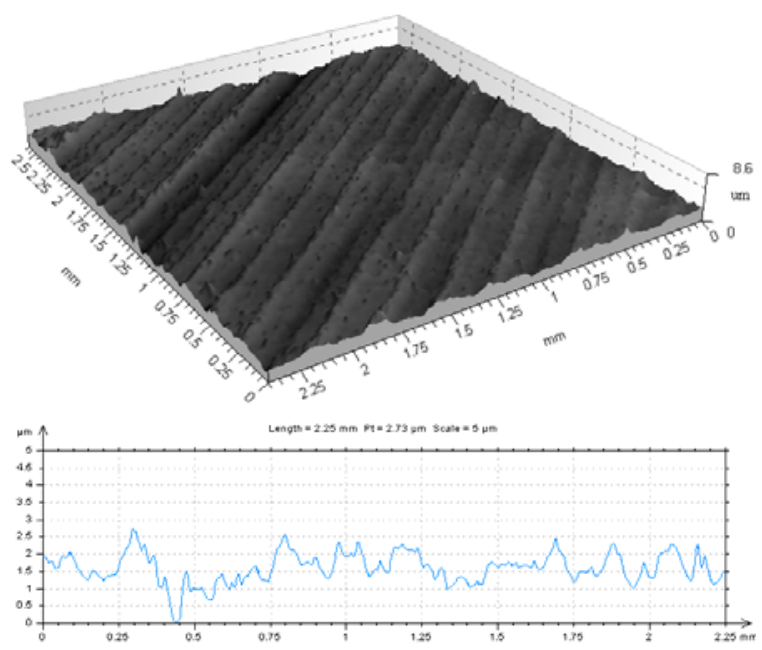

(b)

Figure 3 - Continuous axonometrics and profile extractions for the $100 \mu \mathrm{m}$ trench pattern (B1) - (a) week 0 and (b) week 30 

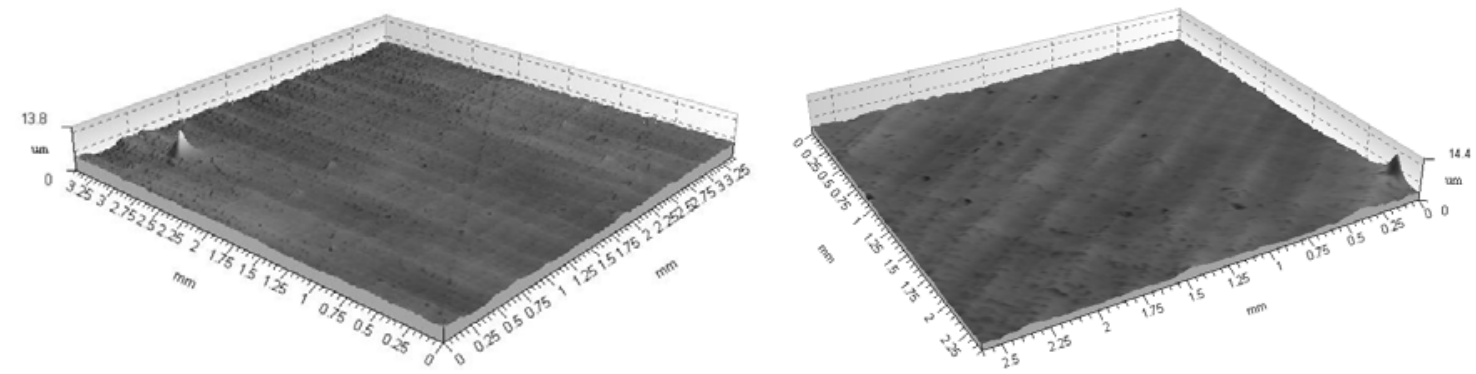

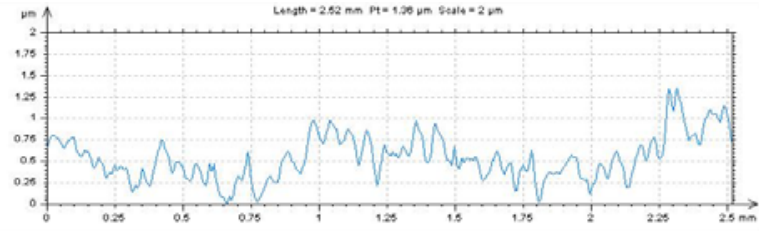

(a)

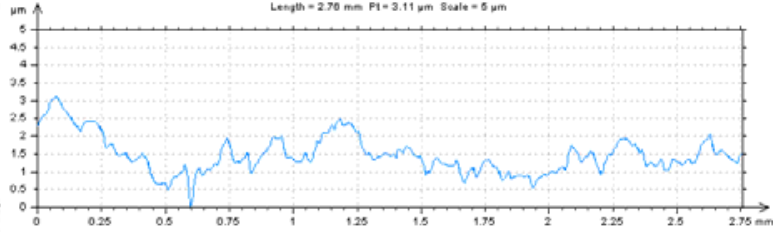

(b)

Figure 4 - Continuous axonometrics and profile extractions for the $50 \mu \mathrm{m}$ hatch pattern (B2) - (a) week 0 and (b) week 30 .

This is owed to the fact that the beam spot size used was $95 \mu \mathrm{m}$ giving rise to overlap of the pattern during processing ultimately eradicating the intended periodicity of the $50 \mu \mathrm{m}$ trench pattern.

Similar to the topography observed for the $50 \mu \mathrm{m}$ trench pattern (see Figure 2), it was found that the 100 $\mu \mathrm{m}$ trench pattern periodicity (see Figure 3 ) did appear to deteriorate after the 30 week study. Furthermore, it can be seen from Figure 3 that the $100 \mu \mathrm{m}$ trench pattern gave rise to peak heights of around $2 \mu \mathrm{m}$ which, coinciding with the as-received sample, did not vary substantially over the 30 week experimentation period. However, slight differences in the roughness parameters, $\mathrm{Sa}$ and $\mathrm{Ra}$, was observed between week 0 and week 30. For example, taking $\mathrm{Sa}$ into consideration, the roughness decreased from $0.375 \mu \mathrm{m}$ to $0.297 \mu \mathrm{m}$ and could be attributed to natural degradation of the surface over the 30 week period. This coincides with most of the laser patterned surface roughness results obtained for the other samples shown in Table 1. Such that the Sa decreased and the Ra either decreased or remained constant over time.

Figure 4 shows the 3-D continuous axonometric and profile extractions for the $50 \mu \mathrm{m}$ hatch patterned sample. From this it can be seen that peak heights between 1 and $2 \mu \mathrm{m}$ were achieved during the laser patterning of the $50 \mu \mathrm{m}$ hatch samples.
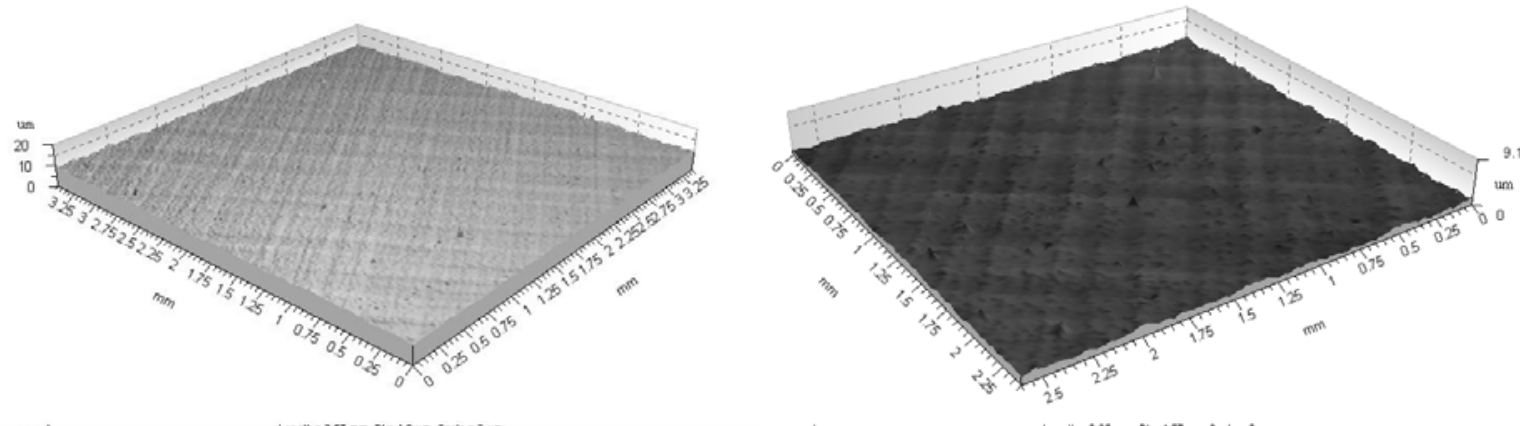

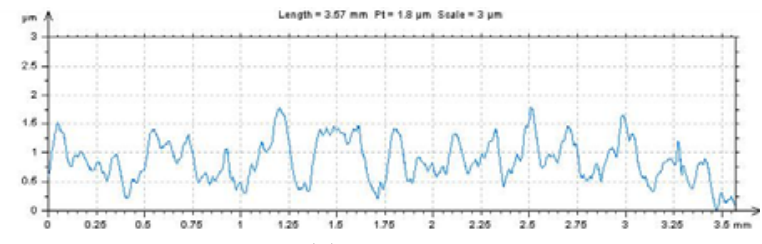

(a)

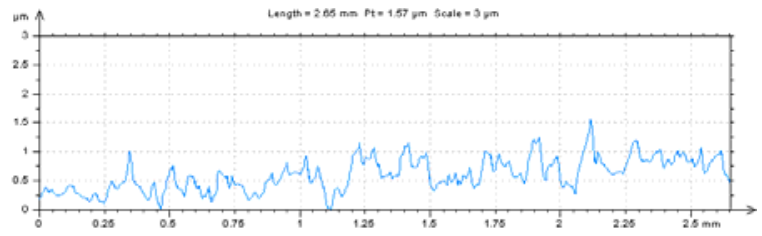

(b)

Figure 5 - Continuous axonometrics and profile extractions for $100 \mu \mathrm{m}$ hatch pattern (B3) - (a) week 0 and (b) week 30 . 
Another factor to note between Figures 4 (a) and (b) is the difference in profile topography. For instance, at week 0 the gradients of the resulting peaks, owed to laser patterning, is somewhat greater than those observed after the 30 week period. This could also be a result of surface degradation. Even though there appeared to be a difference in surface topography, the results given in Table 1 show that the Ra remains somewhat constant over the 30 week period; whereas the Sa roughness was seen to decrease by $0.023 \mu \mathrm{m}$ over the time allotted to study the samples.

Over the 30 week long experiment it was observed, for the laser patterned $100 \mu \mathrm{m}$ hatch sample (see Figure 5) that the peak heights also remained equivalent between 1 and $2 \mu \mathrm{m}$. Additionally, in terms of surface topography Figure 5 shows that, similarly to the $50 \mu \mathrm{m}$ hatch sample (see Figure 4), there was larger gradients for the peaks at week 0 than that of week 30. Again, this could be due to the natural degradation of the sample surface over time.

On a whole it can be seen that there is significant differences in terms of topography when comparing the as-received sample (A1) and the laser patterned samples (A3, B1 - B3). In addition, it was also observed that there appeared to be a significant difference in topography in terms of profile between the laser patterned samples at week 0 and week 30 . That is, the peak heights do not appear to be as sharp as was seen during WLI analysis at week 0 . This is highlighted throughout the profile extractions shown in Figures 2 to 5 .

\section{Wettability and Surface Chemistry}

The recently advancing contact angle for water on the samples was recorded each fortnight over the 30 week experimental period. The results for each sample are given in the graphs shown in Figures 6 and 7. Figure 6 shows the variation in contact angle for the trench patterns (A3 and B1) in comparison to the as-received sample (A1), over the 30 weeks. Similarly, Figure 7 shows the trend in contact angle for the hatch patterns (B2 and B3) also in comparison to the as-received sample (A1). In general, it can be seen that all samples, with the exception of the $50 \mu \mathrm{m}$ trench pattern, display some form of hydrophobic recovery insofar as the characteristic contact angle for these samples increases by up to $10^{\circ}$. This coincides with what has been observed previously through the work of O'Connell et al. [25]. As already stated, the results for the $50 \mu \mathrm{m}$ trench pattern (see Figure 6) do not initially follow the same trend as the other samples due to a reduction in contact angle in the first 4 to 5 weeks. Having said that, it can be seen that after this $4 / 5$ week period that the results for this sample do correlate to the trend which can be identified through the other samples given in Figures 6 and 7.

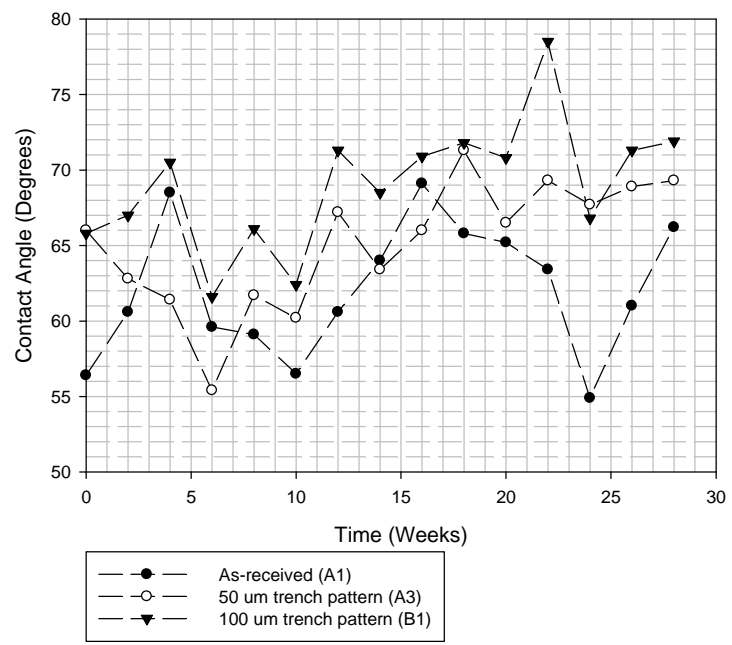

Figure $6-$ Variation of contact angle for samples A1, A3 and B1 over 30 weeks.

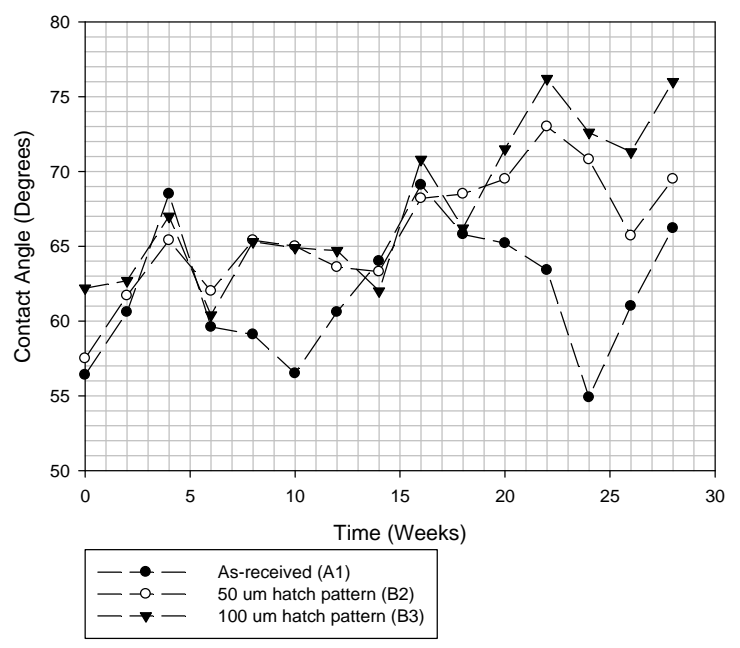

Figure 7 - Variation of contact angle for samples A1, B2 and B3 over 30 weekslaser patterned samples (A3, B1 - B3).

Most work [25,26,31] focuses on the variation of contact angle over 28 days and does not consider any long term effects post- 28 days. This could be of some significance as it can be seen through Figures 6 and 7 that the contact angle dramatically decreases for all samples after the 4 week hydrophobic recovery period. After this time it can be seen that in general each of the samples tended to correlate with one another in terms of hydrophobic loss/recovery. The only difference between each of the samples can be seen through the actual recorded value of recently advanced contact 
angle. For instance, apart from weeks 4, 6, 14 and 16 all laser patterned samples (A3, B1 - B3) gave rise to less hydrophilic contact angles in comparison to the asreceived sample.

There are a number of possible mechanisms which can be linked to hydrophobic loss/recovery and how the wettability of surfaces vary over time. Two of these, as discussed by Kim et al. [31] are reorientation of polar or nonpolar groups and condensation of the surface hydroxyl groups. Another possible mechanism is that of surface degradation which has been observed for the laser patterned samples (A3, B1 - B3). It is even likely that a number of mechanisms may contribute to the resulting contact angle and considerably more work would be required to ascertain the dominating factors.

As the samples, over the 30 weeks, were stored in ambient air it was also necessary to carry out XPS analysis to identify if the oxygen content had varied between weeks 0 and 30 . The results of the XPS analysis can be seen in Table 2 .

Table 2 - XPS data for surface oxygen content for each sample at week 0 and 30 .

\begin{tabular}{|l|c|c|}
\cline { 2 - 3 } \multicolumn{1}{c|}{ Sample } & $\begin{array}{c}\text { Week 0 } \\
\text { Surface Oxygen } \\
\text { Content } \\
\text { (\% At.) }\end{array}$ & $\begin{array}{c}\text { Surface Oxygen } \\
\text { Content } \\
\text { (\% At.) }\end{array}$ \\
\hline $\begin{array}{l}\text { A1 - } \\
\text { As-received }\end{array}$ & 13.26 & 17.38 \\
\hline $\begin{array}{l}\text { A3 - } \\
50 \mu \mathrm{m} \text { trench }\end{array}$ & 14.33 & 21.56 \\
\hline $\begin{array}{l}\mathrm{B} 1- \\
100 \mu \mathrm{m} \text { trench }\end{array}$ & 14.05 & 15.61 \\
\hline $\begin{array}{l}\mathrm{B} 2- \\
50 \mu \mathrm{m} \text { hatch }\end{array}$ & 15.21 & 15.88 \\
\hline $\begin{array}{l}\mathrm{B} 3- \\
100 \mu \mathrm{m} \text { hatch }\end{array}$ & 12.99 & 13.97 \\
\hline
\end{tabular}

As it would be expected, from Table 2 it was found that the surface oxygen content for each of the samples had increased by up to $7.3 \%$ At. This can be attributed to surface oxidation owed to the storage conditions in which the samples were kept in ambient air. It has previously been highlighted by Hao and Lawrence [2] that as a general rule an increase in surface oxygen content should give rise to a reduction in the contact angle. This has not been seen in this instance; however, this could indicate that either another factor is dominant or that a combination of parameters, including surface oxygen content, gave rise to the observed contact angle. In order to determine this, further study is required on the aging and oxidation of laser patterned nylon 6,6.

\section{Atmospheric Parameters}

As with any long term study it was necessary to take into account every possible factor that may have some effect on the contact angle obtained for each of the samples. So, in addition to determining the contact angle every two weeks, atmospheric parameters in terms of pressure, temperature and humidity were recorded. Figures 8 and 9 show graphs of the variation in mean contact angle and atmospheric pressure over the 30 weeks In general it can be seen that a slight trend arises from Figures 8 and 9 such that, on a whole, the contact angle appears to increase with a significant increase in atmospheric pressure.

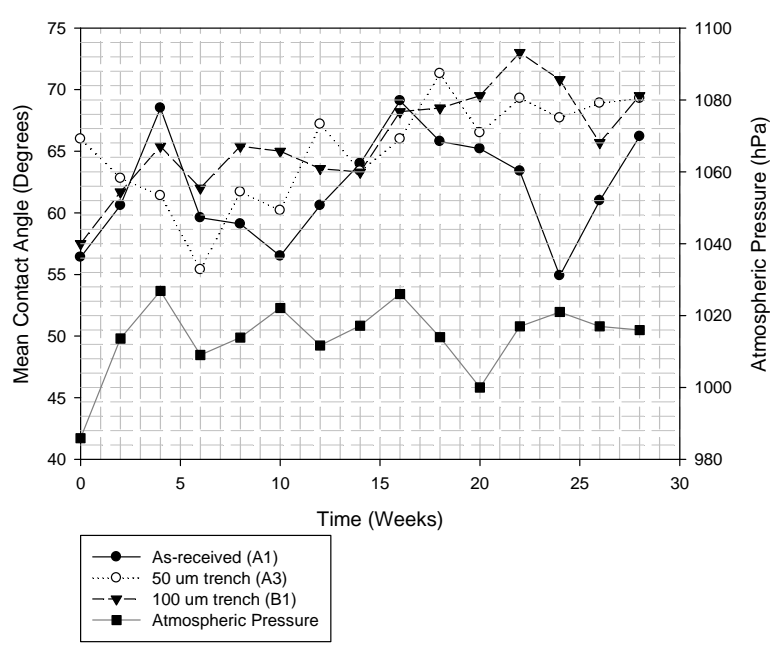

Figure 8 - Variation in mean contact angle for samples A1, A3, B1 and atmospheric pressure over 30 weeks.

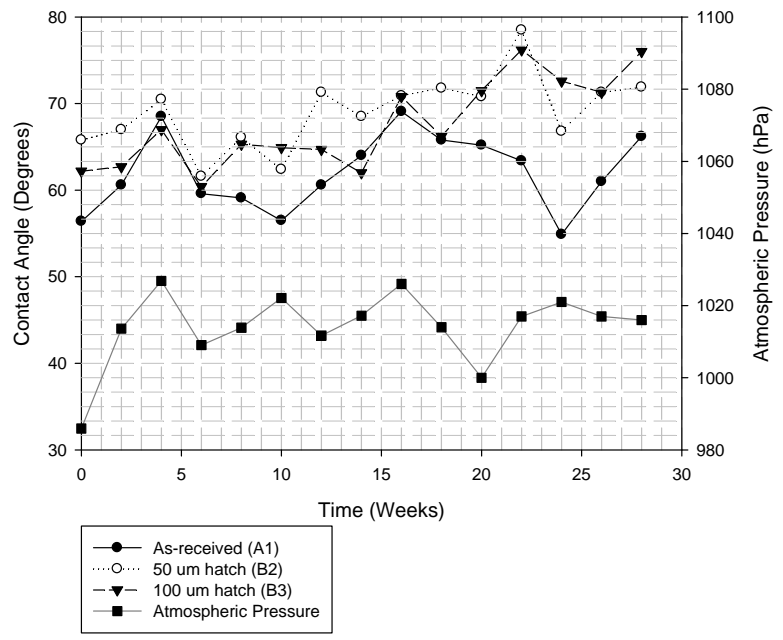

Figure 9 - Variation in mean contact angle for samples A1, B2, B3 and atmospheric pressure over 30 weeks. 
In order to further determine whether this is of any significance, graphs of change in mean contact angle, $\Delta \mathrm{CA}$ and change in atmospheric pressure, $\Delta \mathrm{P}$, for each of the samples over the 30 week period were drawn. These can be seen in Figure 10. The graphs depicted in Figure 10 further highlight the possible correlative trend between the observed contact angle and atmospheric pressure. That is, it can be seen that an increase in contact angle arises when a significant increase in pressure occurs. Furthermore, from the results shown in Figure 8, 9 and 10 significant decreases in the ambient air pressure leads to a noteworthy reduction in the measured contact angle. However, it should be noted that this data alone does not give conclusive results as to the pressure being the dominant factor. This is due to the fact that in some instances the contact angle does not follow this trend. For example, at week 12 the contact angle for the asreceived (see Figure 10 (a)), the $50 \mu \mathrm{m}$ trench (see Figure 10 (b)) and $100 \mu \mathrm{m}$ trench (see Figure 10 (c)) samples gave a relatively large increase in the contact angle regardless of the reduction of up to $10 \mathrm{hPa}$ in barometric air pressure. With these results occurring it is necessary for one to realize that only through continued research will these observations be confirmed.

In regards to the temperature and humidity over the 30 weeks it was found that in this instance no significant correlation could be identified between these parameters and the contact angle obtained for each sample. However, it may be possible that these along with surface roughness and surface chemistry may play a role in the determination of the contact angle. As such, these parameters should not be discarded until further experimentation is carried out.

\section{Conclusions}

This study has confirmed the fact that a relatively inexpensive, low power $\mathrm{CO}_{2}$ laser holds the ability to significantly modify the surface topography of nylon 6,6. Furthermore, it has also been shown that through these surface modifications the wettability of nylon 6,6 can be modified. Through laser patterning of two 50 and $100 \mu \mathrm{m}$ patterns, namely trench and hatch, it was determined that peak heights of up to $3 \mu \mathrm{m}$ could be achieved with $\mathrm{Ra}$ and $\mathrm{Sa}$ values of up to 0.305 and $0.408 \mu \mathrm{m}$, respectively. This is significantly higher when in comparison with the as-received sample which was found to have peak heights of up to $0.2 \mu \mathrm{m}$ with $\mathrm{Ra}$ and Sa values of 0.028 and $0.111 \mu \mathrm{m}$, respectively.

The long term study has identified that after 30 weeks each of the samples studied had become less hydrophilic, with the contact angles increasing by up to $10^{\circ}$. However, over the 30 week period it was observed that the contact angle was erratic, increasing and decreasing rather than converging to a constant value. In terms of topography, surface roughness for the laser patterned samples decreased, in general, over the 30 week period; whereas the roughness of the as-received sample remained constant. It was also found that the surface oxygen content had increased through oxidation owed to the storage of the samples in ambient air. It is likely that these may not be the main driving force owed to the difference in surface roughness between the as-received and laser patterned samples. Furthermore, it has been reported previously that an increase in surface oxygen content should give rise to a reduction in the contact angle.

It is evident through the results obtained that atmospheric pressure may be a main driving force for the observed contact angle. That is, the contact angle in general increases with significant increases of atmospheric pressure and vice versa. Having said that, in some weeks throughout the 30 week period this was not conclusive and allows one to identify that this requires considerably more research in order to determine the main driving forces for the characteristic contact angle. 


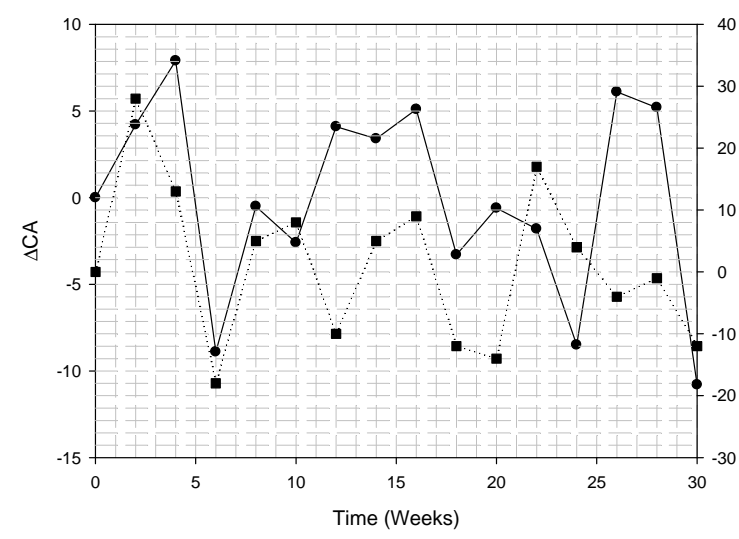

(a)

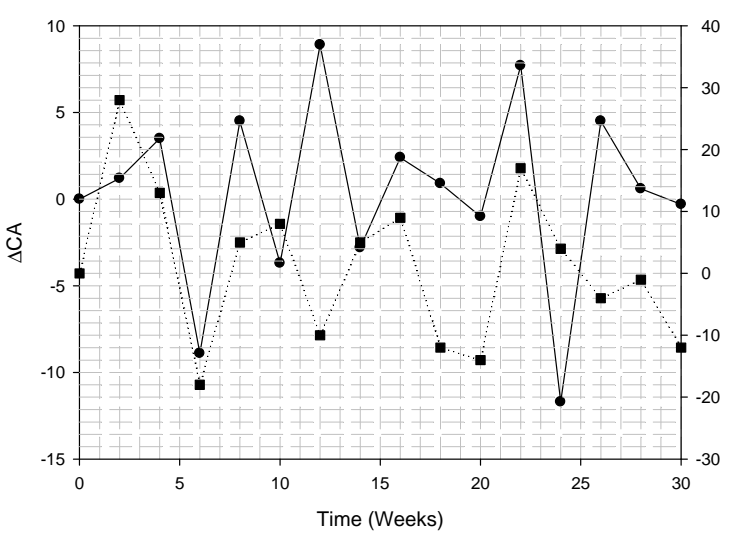

(c)

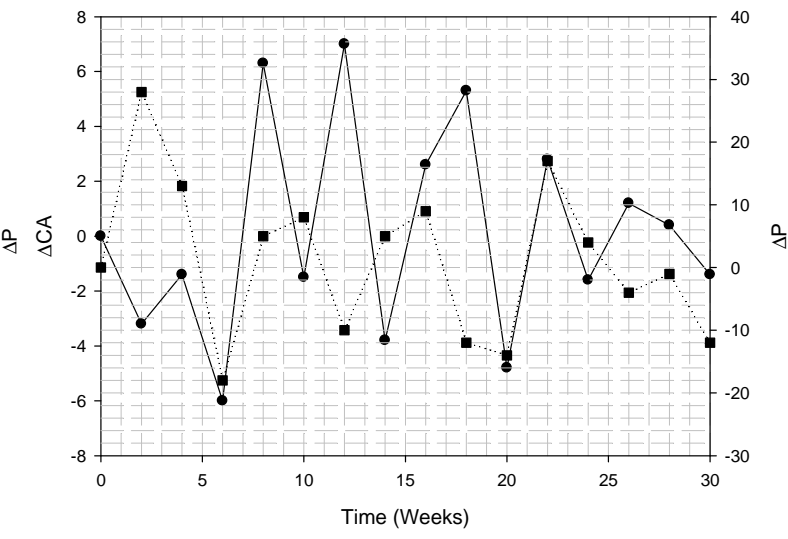

(b)

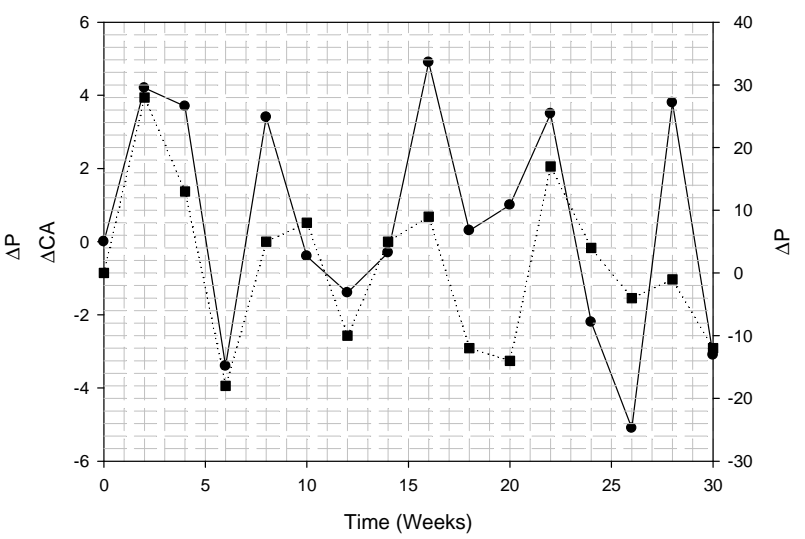

(d)

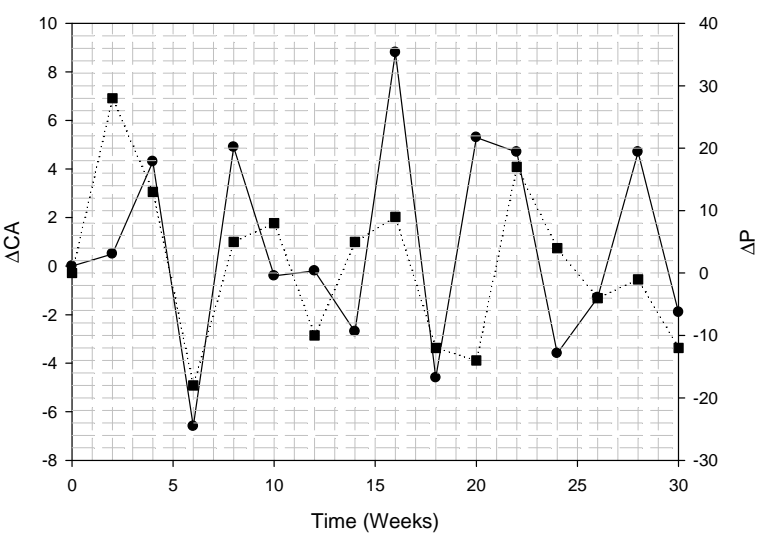

(e)

Figure 10 - Change in contact angle, $\Delta \mathrm{CA}$, and change in pressure, $\Delta \mathrm{P}$, over 30 weeks for (a) as-received (A1), (b) $50 \mu \mathrm{m}$ trench (A3), (c) $100 \mu \mathrm{m}$ trench (B1), (d). $50 \mu \mathrm{m}$ hatch and (e) $100 \mu \mathrm{m}$ hatch. 


\section{Acknowledgements}

We would like to thank our collaborators Directed Light Inc., East Midlands NHS Innovation Hub, Nobel Biocare and Photomachining Inc. for all of their much appreciated support. The authors, particularly DJM, greatly acknowledge the Access to Research Equipment Initiative funded by the EPSRC, (grant number EP/F019823/1). This study is also financially supported by the EPSRC, (grant number EP/E046851/1).

\section{References}

1. Waugh, D.G., Lawrence, J., Morgan, D.J. \& Thomas, C.L. (2009) Interaction of CO2 lasermodified nylon with osteoblast cells in relation to wettability, accepted $30^{\text {th }}$ July 2009, Materials Science and Engineering $\mathrm{C}$.

2. Hao, L. \& Lawrence, J. (2005) Laser Surface Treatment of Bio-implant Materials, John Wiley \& Sons Inc.

3. Kim, M.S., Khang, G. \& Lee, H.B. (2008) Gradient polymer surfaces for biomedical applications. Progress in Polymer Science 33, 138-164.

4. Burton, Z. \& Bhushan, B. (2005) Hydrophobicity, adhesion and friction properties of nanopatterned polymers and scale dependence for micro- and nanoelectromechanical Systems, Nano Letters 5, 16071613.

5. Ouhlal, M., Xu, R. \& Schreiber, H. P. (2004) Adhesion enhancement through control of acid-base interactions, The Journal of Adhesion 80, 467-480.

6. Xu L.C. \& Siedlecki C.A. (2007) Effects of surface wettability and contact time on protein adhesion to biomaterial surfaces, Biomaterials 28, 3273-3283.

7. Spijker, H.T., Graaff, R., Boonstra, P.W., Busscher, H.J. \& Oeveren V.O. (2003) On the influence of flow conditions and wettability on blood material interactions, Biomaterials 24, 4717-4727.

8. Whyman, G., Bormashenko, E. \& Stein, T. (2007) The rigourous derivation of young, Cassie-Baxter and Wenzel equations and the analysis of the contact angle hysteresis phenomenon, Chemical Physics Letters, 450, 355-359.
9. Chen, X. \& Tian, L.U. (2009) The apparent state of droplets on a rough surface, Science in China Series G: Physics, Mechanics \& Astronomy 52, 233-238.

10. Lee, S.M. \& Kwon, T.H. (2007) Effects of intrinsic hydrophobicity on wettability of polymer replicas of a superhydrophobic lotus leaf, Journal of Micromechanics and Microengineering 17, 687-692.

11. Patankar, N.A. (2003) On the modelling of hydrophobic contact angles on rough surfaces, Langmuir 19, 1249-1253.

12. Cheng, Y.T., Rodak, D.E., Wong, C.A. \& Hayden C.A. (2006) Effects of micro- and nano-structures on the self-cleaning behaviour of lotus leaves, Nanotechnology 17, 1359-1362.

13. Jung, Y.C. \& Bhushan, B. (2006) Contact angle, adhesion and friction properties of micro- and nanopatterned polymers for superhydrophobicity, Nanotechnology 4970-4980.

14. Aguilar, C.A., Lu, Y., Mao, S. \& Chen, S. (2005) Direct micro-patterning of biodegradable polymers using ultraviolet and femtosecond lasers, Biomaterials $267642-7649$.

15. Yu, F., Mucklich, F., Li, P., Shen, H., Mathur, S., Lehr, C.M. \& Bakowsky, U. (2005) In vitro cell response to a polymer surface micropatterned by laser interference lithography, Biomacromolecules 6, 11601167.

16. Chu, P.K. (2007) Enhancement of surface properties of biomaterials using plasma-based technologies, Surface and Coatings Technology 201, 8076-8082.

17. Wei, Q., Liu, Y., Hou, D. \& Huang, F. (2007) Dyanmic wetting behaviour of plasma treated PET fibers, Journal of Materials Processing Technology 194, 89-92.

18. Zhao, Q., Wang, C. Liu, Y. \& Wang, S. (2007) Bacterial adhesion on the metal-polymer composite coatings, International Journal of Adhesion \& Adhesives 27, 85-91.

19. Lord, M.S., Cousins, B.G., Doherty, P.J., Whitelock, J.M., Simmons, A., Williams, R.L. \& Milthorpe, B.K. (2006) The effect of silica nanoparticulate coatings on serum protein adsorption and cellular response, Biomaterials 27, 4856-4862. 
20. David, C., Wei, J., Lippert, T. \& Wokaun, A. (2001) Diffractive grey-tone phase masks for laser ablation lithography, Microelectronic Engineering 57$58,453-460$.

21. Benson, R.S. (2002) Use of radiation in biomaterials Science, Nuclear Instruments and Methods in Physics Research B 191, 752-757.

22. Mirzadeh, H. \& Dadsetan, M. (2003) Influence of laser surface modifying of polyethylene terephthalate on fibroblast cell adhesion, Radiation Physics and Chemistry 67, 381-385.

23. Rajesh, J.J., Bijwe, J., Venkataraman, B. \& Tewari, U.S. (2002) Effect of water absorption on erosive wear behaviour of polyamides, Journal of Materials Science $37,5107-5113$.

24. Monson, L., Braunworth, M. \& Extrand, C.W. (2008) Moisture absorption by various polyamides and their associated dimensional changes, Journal of Applied Polymer Science 107, 355-363.

25. O'Connell, C., Sherlock, R., Ball, M.D., AszalosKiss, B., Prendergast, U. \& Glynn, T.J. (2009) Investigation of the hydrophobic recovery of various polymeric biomaterials after $172 \mathrm{~nm}$ UV treatment using contact angle, surface free energy and XPS measurements, Applied Surface Science 255, 44054413.

26. Ross, G.G., Chasse, M. \& Bolduc M. (2003) Effect of ageing on wettability of quartz surfaces modified by Ar implantation, Journal of Physics D: Applied Physics 36, 1001-1008.

27. Li, Y., Pham, J.Q., Johnston, K.P. \& Green P.F. (2007) Contact angle of water on polystyrene thin films: Effects of $\mathrm{CO}_{2}$ environment and film thickness, Langmuir 23, 9785-9793.

28. Hansen, G., Hamouda, A.A. \& Denoyel, R. (2000) The effect of pressure on contact angles and wettability in the mica/water/n-decane system and the calcite+stearic acid/water/n-decane system. Colloids and Surfaces A: Physicochemical and Engineering Aspects 172, 7-16.

29. Siemons, N., Bruining, H., Castelijns, H. \& Wolf, K.H. (2006) Pressure dependence of the contact angle in a $\mathrm{CO}_{2}-\mathrm{H}_{2} \mathrm{O}$-coal system, Journal of Colloid and Interface Science 297, 755-761.
30. Rance, D.G. (1982) Chapter 6 - thermodynamics of wetting: From its molecular basis to technological application. In: Brewis DM, editor. Surface Analysis and Pretreatment of Plastics and Metals, Applied Science Publishers, 121pp.

31. Kim, J., Chaudhury, M.K., Owen, M.J. \& Orbeck, T. (2001) The mechanisms of hydrophobic recovery of polydimethylsiloxane elastomers exposed to partial electrical discharges, Journal of Colloid and Interface Science 244, 200-207.

\section{Meet The Author}

David Waugh is currently undertaking a $\mathrm{Ph}$.D. at the Wolfson School of Mechanical and Manufacturing Engineering, Loughborough University, UK under the supervision of Dr. Jonathan Lawrence. His research is focusing on using laser surface treatment of polymeric biomaterials for enhanced cell response. He obtained his MPhys Hons. in Physics with Lasers and Photonics and MSc in Laser Applications in Micro-Machining and Processing from the University of Hull, UK. 